\title{
IDEOLOGIAS LINGUÍSTICAS: UMA BREVE ANÁLISE DA BNCC
}

\author{
Ideologías Linguísticas: Un Breve Análisis del BNCC
}

\author{
Alexandra Nunes SANTANA \\ Universidade Estadual de Ponta Grossa \\ alexandransantana24@gmail.com \\ https://orcid.org/0000-0001-6745-3627
}

RESUMO: O presente trabalho tem como objetivo realizar uma breve análise da nova Base Nacional Comum Curricular (BNCC). Mais especificamente, o foco recai sobre a disciplina de Língua Portuguesa, com o intuito de observar que/quais ideologia(s) linguística(s) para o ensino da língua portuguesa está(ão) sendo imposta(s), já que a BNCC "é um documento de caráter normativo que define o conjunto orgânico e progressivo de aprendizagem essenciais que todos os alunos devem desenvolver ao longo das etapas e modalidades da Educação Básica" (BRASIL, 2017, p. 7), para ser (em) trabalhada(s) em sala de aula. Para isso, visitamos alguns estudiosos, como Bagno (2007, 2011, 2013, 2014), Woolard (1998), Moita Lopes (2013), Cavalcanti (2007, 2013), Eagleton (2011), César e Cavalcanti (2007) e Milroy (2011) para a reflexão sobre ideologias linguísticas. Em relação à linguagem, baseamo-nos, principalmente, nas postulações do Círculo de Bakhtin. Diante disso, percebemos a necessidade de o/a professor/a estar atento/a à concepção de língua adotada pela BNCC e de como se dará o ensinoaprendizado da língua portuguesa nas salas de aulas do país.

PALAVRAS-CHAVE: BNCC; Ideologias Linguísticas; Políticas Linguísticas; Língua Portuguesa.

RESUMEN: Este documento tiene como objetivo realizar un breve análisis de la nueva Base Curricular Común Nacional (BNCC). Más específicamente, la atención se centra en la disciplina de la lengua portuguesa, a fin de observar que/cuales ideología (s) lingüística (s) para la enseñanza de la lengua portuguesa se está imponiendo, ya que el BNCC "es un documento normativo que define el conjunto esencial de aprendizaje orgánico y progresivo que todos los estudiantes deben desarrollar a lo largo de las etapas y modalidades de Educación Básica" (BRASIL, 2017, p. 7), para trabajar en aula. Para eso, visitamos algunos expertos, como Bagno (2007, 2011, 2013, 2014), Woolard (1998), Moita Lopes (2013), Cavalcanti (2007, 2013), Eagleton (2011), César y Cavalcanti (2007) y Milroy (2011), por la reflexión sobre ideologías linguiísticas. En relación con el lenguaje, nos basamos principalmente en las postulaciones del Círculo de Bakhtin. En vista de esto, nos dimos cuenta de la necesidad de que el maestro sea consciente del concepto de 
lenguaje adoptado por el BNCC y de cómo la enseñanza y el aprendizaje del idioma portugués se llevarán a cabo en las aulas del país.

PALABRAS CLAVE: BNCC; Ideologías Lingüísticas; Políticas Lingüísticas; Lengua Portuguesa.

\section{CONSIDERAÇÕES INICIAIS}

O Brasil sofre com índices nada satisfatórios em avaliações de larga escala (como PISA, Programa Internacional de Avaliação de Estudantes, e Enem, Exame Nacional do Ensino Médio), internamente, e também em relação aos outros países, como Finlândia, Japão e Suécia que apresentam os melhores sistemas de ensino e lideram o ranking de avaliações internacionais. Diante desse quadro e com a intenção de "diminuir" a desigualdade no ensino/aprendizagem que ocorre entre os estados e municípios da Nação foi formulado um documento que define as aprendizagens essenciais que todos os/as alunos/as devem desenvolver ao longo da Educação Básica, a Base Nacional Comum Curricular (BNCC).

A BNCC é referência nacional e obrigatória para a (re)organização curricular dos sistemas e das redes escolares dos estados, do DF e dos municípios e tem como um dos propósitos direcionar a educação brasileira para a formação humana integral e para a construção de uma sociedade justa, democrática e inclusiva (BRASIL, 2017, p. 7).

Refletindo um pouco sobre a questão de haver um currículo único para todo o país, torna-se necessário realizar uma análise da BNCC sobre que(quais) ideologia(s) linguística(s) está(estão) sendo galgadas para o ensino/aprendizagem da língua portuguesa.

Vale assinalar que a implementação de um currículo único pode reforçar uma visão de cultura homogênea, assim como de língua única/homogênea e isso é preocupante, pois essas ideologias afetam o ensino/aprendizagem da língua portuguesa, porque deixam de abordar de maneira mais significativa a diversidade linguística e cultural que se manifesta no cotidiano, nas práticas sociais.

Por isso, reservamos um espaço para falar sobre ideologia linguística. Assim temos o intuito de responder as seguintes questões: Como a BNCC trata o fenômeno da heterogeneidade/variação linguística? Que ideologia(s) linguística(s) está(ão) presente(s) 
no documento e, consequentemente, que ideologia(s) linguística(s) deverá(ão) estar presentes nas salas de aula do país?

Enfim, este trabalho tem o objetivo de identificar e analisar a(s) ideologia(s) linguística(s) que está(ão) sendo perpassada(s) no ensino de língua portuguesa no que se refere à questão da heterogeneidade/variação linguística.

\section{REVISITANDO A LITERATURA}

Ensinar a língua portuguesa em sala de aula durante toda a educação básica não é tarefa fácil. Envolve saberes e práticas complexos que vão desde as concepções de língua/linguagem, as ideologias linguísticas e passa pelas definições do quê e do como ensinar (SANTANA, 2017). Pensando nessa complexidade, buscamos definições desses conceitos à luz dos estudos do Círculo de Bakhtin.

Para Bakhtin (2011, p. 261), o conceito de linguagem, está inteiramente relacionado com "todos os diversos campos da atividade humana". Esses campos, ou esferas sociais, são todas as áreas e instituições sócio historicamente construídas em que o processo comunicativo acontece, como por exemplo, no âmbito político, religioso, científico, publicitário, literário, cotidiano, escolar etc. Desta maneira,

todo trabalho de investigação de um material linguístico concreto - seja de história da língua, de gramática normativa, de confecção de toda espécie de dicionário ou estilística da língua, etc. - opera inevitavelmente com enunciados concretos (escritos e orais) relacionados a diferentes campos da atividade humana e da comunicação - anais, tratados, textos de leis, documentos de escritório e outros, diversos gêneros literários, científicos, publicísticos, cartas oficiais e comuns, réplicas de diálogo cotidiano (em todas as suas diversas modalidades), etc. (BAKHTIN, 2011, p. 264).

O autor afirma, ainda, que "o caráter e as formas desse uso são tão multiformes quanto os campos da atividade humana" (BAKHTIN, 2011, p. 261). Percebe-se, então, que dentro de cada um desses âmbitos há infinitas formas de a linguagem ser constituída e utilizada. Sendo assim, quando se pensa no ensino da língua portuguesa, que é o foco deste estudo, é importante ter como pressuposto da prática pedagógica a heterogeneidade da língua. 
Bakhtin (2011, p. 261) assinala que "o emprego da língua se efetua em forma de enunciados" em suas diferentes formas, sejam orais ou escritos, de acordo com a necessidade/finalidade do processo de interação. Ou seja, como a língua é viva, ela sempre está em movimento, em mudança. Então, para que haja interação, é necessário que as pessoas que estão interagindo compartilhem o extraverbal, que dá sustentação ao verbal. Para Bakhtin/Voloshinov, "qualquer que seja o aspecto da expressão-enunciação considerado, ele será determinado pelas condições reais da enunciação em questão" (2009, p. 116); por isso, no ensino/aprendizagem de língua, torna-se necessário trabalhar com situações concretas de enunciação para que os/as alunos/as aprendam usar diferentes recursos linguísticos e apreendam distintos efeitos de sentido que esses usos podem promover, posto que "a enunciação é o produto da interação de (...) indivíduos socialmente organizados" (BAKHTIN/VOLOSHINOV, 2009, p. 116). Assim, "a situação social mais imediata e o meio social mais amplo determinam completamente e, por assim dizer, a partir do seu próprio interior, a estrutura da enunciação" (2009, p. 117). Esta estrutura diz respeito à estrutura composicional e também aos recursos linguísticos aí utilizados.

Diante disso, é muito relevante ressaltar que é necessário que o/a professor/a tenha consciência de que, no processo de ensino/aprendizagem de uma língua, está trabalhando com enunciados, dirigidos a alguém e orientados por um projeto de dizer. Cada enunciado "é um elo real na cadeia da comunicação discursiva em determinado campo da atividade humana ou da vida" (BAKHTIN, 2011, p. 288). É claro também que "cada enunciado particular é individual, mas cada campo de utilização da língua elabora seus tipos relativamente estáveis de enunciados" (BAKHTIN, 2011, p. 262, grifos do autor). Isto é, como já mencionado, "a língua passa a integrar a vida através de enunciados concretos (que a realizam); é igualmente através de enunciados concretos que a vida entra na língua (BAKHTIN, 2011, p. 265).

Para Bakhtin (2011, p. 270), "a língua é deduzida da necessidade do homem de autoexpressar-se, de objetivar-se", mas para que isso ocorra é necessário o outro, ou seja, as relações de alteridade entres os falantes, que geram as cadeias de respostas entre os sujeitos e aos enunciados. Sendo assim, a compreensão do enunciado está relacionada/gera uma ação responsiva do ouvinte, mesmo que essa compreensão responsiva seja de efeito 
retardado; cedo ou tarde, "o que foi ouvido e ativamente entendido responde nos discursos subsequentes ou no comportamento do ouvinte" (p. 272).

Desta forma, no processo de ensino/aprendizagem de uma língua, é primordial trabalhar com enunciados, isto é, com as várias manifestações concretas de uso da língua. Essas manifestações compreendem uma ampla gama de diversidade linguística, uma vez que remete à diversidade de posições sociais, históricas e ideológicas dos sujeitos e dos grupos. Essa diversidade linguística é concebida por Bakhtin como diversas línguas sociais: "modos de falar de grupos, jargões profissionais, as linguagens dos gêneros, as das gerações e das faixas etárias, as linguagens das tendências e dos partidos, as linguagens das autoridades, as linguagens dos círculos e das modas passageiras" etc. (BAKHTIN, 2015, p. 30). Essas línguas acontecem nos enunciados. As línguas sociais, sob um certo aspecto/enfoque, podem ser aproximadas da perspectiva sociolinguística de variação linguística, e, por isso, é primordial dar a devida importância ao tratamento da heterogeneidade/variação linguística.

O principal papel da escola é de poder contribuir na formação dos/das alunos/as para o exercício da cidadania, proporcionando ao/à aluno/a, no que diz respeito ao ensino de língua, o aprendizado dos vários recursos para o seu uso, dentre os quais, é claro, estão as variedades cultas. É muito importante que o/a estudante tenha domínio dessas variedades para poder usá-las em momentos da atividade humana nos quais elas se fazem necessárias, o que não significa priorizar somente o ensino dessas variedades e menosprezar as outras, como se na escola não fosse lugar destas, não fosse lugar do multilinguismo em língua portuguesa (CAVALCANTI, 2013). O respeito e a valorização das variedades linguísticas decorrem da compreensão de que elas são utilizadas na comunicação entre pessoas de várias camadas sociais, de culturas diferentes, de modos distintos de pensar e de usar as línguas, em razão de que, em "um grupo linguístico, a multiplicidade de falantes evidentemente não pode ser ignorada de maneira nenhuma quando se fala da língua" (BAKHTIN, 2011, p. 270).

Nessa perspectiva teórico-metodológica do Círculo de Bakhtin, não se pensa a língua como um sistema de categorias gramaticais abstratas, mas sim, como ideologicamente preenchida, a língua enquanto cosmovisão e até como uma opinião concreta que assegura o maximum de compreensão mútua em todos os campos da vida ideológica” (BAKHTIN, 2015, p. 40). Considerando que há diferentes grupos, com 
distintas cosmovisões e conjuntos de valores, compreende-se que há distintas línguas sociais. É neste sentido que buscamos articular a noção de multilinguismo em línguas portuguesas (CAVALCANTI, 2007), tomadas como distintas estruturas linguísticas, à concepção de língua como cosmovisão/conjunto de valores, como ideologicamente preenchida.

O/a professor/a que apreende a língua como interação social e como cosmovisão compreende que "a escolha de todos os recursos linguísticos é feita pelo falante sob maior ou menor influência do destinatário e da sua resposta antecipada" (BAKHTIN, 2011, p.306, grifos do autor) e, ainda, que "a análise estilística, que abrange todos os aspectos do estilo, só é possível como análise de um enunciado pleno e só naquela cadeia da comunicação discursiva da qual esse enunciado é um elo inseparável” (p. 306, grifos do autor).

Assim sendo, percebe-se que no processo de ensino/aprendizagem de uma língua não precisa ser priorizado o ensino sistemático da língua, mas, sim, o seu uso nas diversas relações sociais, como ela é carregada ideologicamente/valorativamente nas diversas esferas da atividade humana.

\section{IDEOLOGIA LINGUÍSTICA}

É realidade que as pesquisas avançaram, que os documentos oficiais reconhecem o multilinguismo na nossa sociedade. No entanto, mesmo assim, ainda há o predomínio em nosso país de orientação para o ensino da língua padronizada. Para Milroy (2011, p. 57), "um efeito extremamente importante da padronização tem sido o desenvolvimento da consciência, entre os falantes, de uma forma de língua "correta" ou canônica". O autor salienta que "praticamente todo mundo adere à ideologia da língua padrão e um aspecto dela é uma firme crença na correção" (idem), ou seja, essa ideologia distorce a realidade em favor das necessidades de um grupo, os formuladores e defensores da norma-padrão que frequentemente se opõem às variedades populares e às das variedades cultas faladas no Brasil (FARACO, 2008). Nesse sentido, ainda predomina em muitas orientações para o ensino da língua portuguesa a ideologia da língua padrão, vinculada também aos grupos dominantes, que é uma ideologia linguística. 
De acordo com Woolard (1998, p. 5), o termo "ideologia" foi cunhado pela primeira vez no final do século XVIII pelo filósofo francês Destutt de Tracy que esperava desenvolver uma ciência das ideias, tomando-se ideias no sentido bem amplo de estados da consciência. Para a autora, ao termo foi logo dada a sua conotação negativa no esforço de Napoleão em desacreditar Destutt de Tracy e seus colegas, cuja posição institucional e trabalho estavam ligados ao republicanismo. No uso de Napoleão, a ideologia tornou-se "mera" e "ideóloga" um epíteto desprezível para os proponentes de teorias abstratas não baseadas ou apropriadas para as realidades humanas e políticas. Nas palavras da autora, o negativismo napoleônico provou ser duradouro, de modo que essa concepção de ideologia ainda é uma variação significativa mesmo entre os significados científicos sociais do termo.

Segundo Eagleton (1997, p. 15) "ninguém propôs ainda uma definição única e adequada de ideologia", isso porque "o termo "ideologia" tem toda uma série de significados convenientes, nem todos eles compatíveis entre si”. Segundo o autor, a palavra "ideologia" é, “[...] um texto, tecido com uma trama inteira de diferentes fios conceituais; é traçado por divergentes histórias, e mais importante, provavelmente, do que forçar essas linhagens e reunir-se em alguma Grande Teoria Global é determinar o que há de valioso em cada uma delas e o que pode ser descartado" (idem).

Para Moita Lopes (2013, p. 19), um dos autores que mobiliza os referenciais dos estudos de ideologias linguísticas no Brasil, vivemos em um tempo em que "a linguagem passa a ocupar um espaço diferenciado em nossas vidas sociais, o que precisa ser considerado em relação ao que chamamos de português". Para o autor, "ideologias linguísticas envolvem tanto os modelos socioculturais da linguagem em uso, do que chamamos de português no nosso caso, construídos pelos falantes, escritores etc., como também aqueles elaborados por especialistas do campo dos estudos da linguagem"(idem). E acrescenta,

\footnotetext{
entendemos por ideologia linguística as compreensões, tanto explícitas quanto implícitas, que traduzem a interseção da linguagem e os seres humanos em um mundo social (Woolard, 1998:3) ou compreensões de como a linguagem ou línguas específicas têm sido ou são entendidas com base em como são situadas em certas práticas sócio históricas, inclusive aquelas visões elaboradas por pesquisadores e teóricos da linguagem, derivadas do espírito intelectual ou da perspectiva epistemológica de seu tempo (MOITA LOPES, 2013, p. 22).
} 
Nesse sentido, nenhum "conhecimento é privilegiado ou que nenhuma teoria é transparente ou tem acesso à verdade" (MOITA LOPES, 2013, p. 22). Moita Lopes também destaca em seu trabalho cinco dimensões abarcadas por Kroskrity (2004) para desenvolver a noção de ideologia linguística. Kroskrity propõe a divisão, mas enfatiza que essas dimensões muitas vezes se sobrepõem.

A primeira dimensão refere-se ao fato de que as ideologias linguísticas refletem os interesses de um grupo social e cultural específico. Um exemplo é o da "ideologia linguística da norma, que desampara sociolinguisticamente aqueles que não dominam a língua considerada legítima" (MOITA LOPES, 2013, p. 23). Segundo Faraco, que também reflete sobre os valores da língua padrão na sociedade, essa ideologia distorce a realidade em favor das necessidades de um grupo, os formuladores e defensores da normapadrão que se opuseram com cólera às características das variedades populares e às das variedades cultas faladas no Brasil (FARACO, 2008).

A grande valorização da norma padrão, dos ideais de correção, na nossa sociedade, configura, portanto, ideologias linguísticas, uma vez que diz respeito ao modo como, na nossa sociedade, se considera o que seja língua e o que sejam usos linguísticos corretos e, por consequência, legítimos. Essa ideologia da padronização está relacionada à ideologia do monolinguismo. Além de haver uma língua correta, há também o ideal de que apenas essa língua representa o ideal de unidade nacional. Essa língua, que é identificada à norma-padrão, é vista como a única língua capaz de garantir a unidade da nação.

A segunda dimensão está relacionada ao fato de as ideologias linguísticas serem variadas, uma vez que os significados sociais "se referem a uma multiplicidade de divisões sociais de gênero, classe social, geração, sexualidade, nacionalidade, etc., que de fato se entrecortam" (MOITA LOPES, 2013, p. 23). A terceira dimensão, por sua vez, está relacionada ao fato de que "a consciência que os participantes de um grupo específico têm das ideologias linguísticas que adotam é variável", ou seja, "nem sempre os participantes demonstram consciência explícita das ideologias linguísticas que geram seus usos" (idem).

Já a quarta dimensão alude ao fato de as ideologias linguísticas "fazerem a mediação entre as estruturas sociais e a linguagem em uso". Essa mediação é assinalada pelas "indexicalizações linguísticas e discursivas no uso da linguagem que se referem às experiências socioculturais dos falantes e escritores", quer dizer, "índices das 
performances identitárias e das práticas discursivas em que eles estão envolvidos" (MOITA LOPES, 2013, p. 25).

A quinta dimensão refere-se ao fato de que as ideologias linguísticas têm a ver "com o modo como elas são usadas na construção de identidades culturais e nacionais, tais como nacionalidade e etnia" (MOITA LOPES, 2013, p. 27). Segundo o autor, "o fenômeno de compartilhamento de uma língua tem sido utilizado para separar ou dividir grupos sociais, construindo diferenças de várias naturezas entre os grupos, tornando-as naturais, favorecendo a construção do estado-nação", isso, muitas vezes, "ao preço do aniquilamento de outras línguas/variedades ou de seu apagamento" (idem). No caso do Brasil, a ideologia do monolinguismo da língua portuguesa, que é construída discursivamente como elemento da unidade nacional brasileira, tem silenciado as inúmeras línguas indígenas, de imigrantes, de fronteiras, de sinais (CAVALCANTI, 1999). No Brasil, como afirmam César e Cavalcanti (2007, p. 50), "na área dos estudos da linguagem, as práticas pedagógicas refletem o ideal do monolinguismo, sob a égide do português como língua oficial", por isso, "amargam índices crescentes de fracasso escolar dos seus estudantes falantes de línguas minoritárias”. Sendo assim, como afirma Moita Lopes (2013, p. 27), “a ideologia da delimitação linguística a uma comunidade precisa ser revista, principalmente à luz dos processos de globalização e de fronteiras porosas que vivenciamos", ou seja, é necessário compreender que as ideologias linguísticas são muito mais complexas (envolvem diferentes dimensões e aspectos sociais, históricos e políticos) e que as línguas também são construtos sociais muito mais complexos (línguas são constitutivamente heterogêneas e hibridizáveis/hibridizadas) para dar conta do que entendemos como português no século XXI. "Esse posicionamento significa que ideologias linguísticas são motivadas por interesses específicos, valores e visões do mundo e do ser humano nele" (MOITA LOPES, 2013, p. 27).

Para Bakhtin/Voloshinov, a língua incorpora e articula a experiência social, a luta, a transição e competição, e, consequentemente, o signo linguístico é visto como profundamente ideológico (ELICHIRIGOITY, 2008). Já em Marxismo e filosofia da linguagem, Bakhtin/Voloshinov (1995) os autores questionam em que medida a linguagem determina a consciência, e, em que medida a ideologia determina a linguagem. Por isso é muito importante que o/a professor/a tenha consciência de que ideologia de 


\section{REVISTA $\mathbf{X}$}

língua está transmitindo às/aos suas/seus alunas/os, já que a ideologia da normalização continua a ser soberana.

É claro que não podemos desconsiderar que o papel da escola é proporcionar às/aos estudantes o aprendizado da variedade culta e que é importante que a/o aluna/o tenha domínio dessa variedade para poder usá-la em momentos que se fazem necessário. Mas a variedade linguística deve ser respeitada e valorizada, pois ela é utilizada como meio de comunicação entre pessoas de várias camadas sociais, de culturas diferentes, de modos distintos de pensar e de usar a língua.

Acreditamos que o objetivo da escola é fazer com que o estudante, como salienta Signorini (2004, p. 90), faça "uso adequado da escrita e dos materiais escritos em diferentes contextos, ou, mais genericamente ainda, ler/interpretar e escrever de maneira adequada em diferentes contextos". Para a autora, esse "adequado" seria

trabalhar com alternativas de leitura/escrita que não reproduzam a lógica diglóssica de dicotomias estanques do tipo: ou é padrão ou não padrão, culto ou inculto, letrado ou não letrado, oral ou escrito, formal ou informal etc. A observação das práticas reais e das formas em circulação, ou seja, a observação dos usos contextualizados, mostra como são de fato movediços limites assim traçados e frágeis as relações de oposição assim demarcadas (SIGNORINI, 2004, p. 98).

Diante do que foi levantado sobre ideologia linguística, não podemos ignorar o peso que a cultura do "erro" tem em nosso país "peso que tem impedido uma discussão mais aberta e menos preconceituosa de nossa cara linguística real (FARACO, 2008, p. 178). Partindo desta perspectiva de ideologias linguísticas, paramos para refletir a concepção de “erro" e o preconceito linguístico, para podermos compreender que ideologia linguística disseminamos na escola para o ensino de língua portuguesa.

\section{A CONCEPÇÃO DE “ERRO” E O PRECONCEITO LINGUÍSTICO}

É muito comum ouvir em sala de aula os/as alunos/as afirmarem o seguinte: "Não sabe nem português, como vai aprender uma língua estrangeira? Percebemos nessa afirmação que as/os alunas/os acreditam que não dominam o uso da língua portuguesa, porém o que elas/eles não dominam com eficiência é a tal da norma culta da língua. Essa visão de não saber a língua é reflexo de um grande preconceito linguístico que ocorre na 
sociedade, uma vez que a ideologia da padronização é muito forte no que se refere ao ensino/aprendizagem da língua portuguesa, tanto por parte de professores (de línguas e de outras disciplinas) quanto por parte da sociedade de modo geral. Tudo isso porque vivemos uma cultura de que tudo que é escrito ou falado diferente da norma padrão não é “correto", "é errado", como observamos anteriormente a partir de Milroy (2011). A ideologia da padronização é bastante forte em diversas sociedades, especialmente porque alguns dos principais espaços de difusão dela são a escola e a mídia. O ensino da normapadrão se caracteriza como a difusão e o reforço dessa ideologia. E a escola assume o papel de ensinar essa norma, portanto, de propagar e enfatizar essa ideologia.

Como diz Faraco (2008, p. 80), “os formuladores e defensores da norma-padrão se opuseram com igual furor às características das variedades populares e às das variedades cultas faladas aqui [no Brasil]". O autor afirma ainda que "o excessivo artificialismo do padrão que estipularam impediu, porém, que ele se estabelecesse efetivamente entre nós". O que Faraco defende é que a norma-padrão não é utilizada nem mesmo pelos brasileiros mais letrados; o que esses falantes têm utilizado realmente é uma "variedade prestigiada" que não segue todas as regras da padronização, mas que tem estado presente em várias esferas comunicativas, como por exemplo, na mídia (escrita e televisiva), nas propagandas, nos livros, nas escolas, nas igrejas, etc.

As noções de "certo" ou "errado" ainda são muito difundidas, principalmente, nos livros didáticos. Os livros são repletos de exercícios que se limitam a considerar "corretas" apenas as formas prescritas nas gramáticas normativas, que se dedicam a orientar os/as alunos/as a corrigir erros em textos que circulam socialmente. E assim sendo, essa “correção linguística e o prestígio atribuído às variedades cultas estão diretamente ligados à maior ou menor semelhança com a norma-padrão tradicional" (CHAMA, 2007, p. 19). Por isso, o preconceito linguístico está inteiramente relacionado à noção de "erro", já que este "empobrece" a língua e a torna cada dia mais "deplorável" (CHAMA, 2007, p. 20). Bagno afirma que

do ponto de vista científico, simplesmente não existe erro de português. Todo falante nativo de uma língua é um falante plenamente competente dessa língua, capaz de discernir intuitivamente a gramaticalidade ou agramaticalidade de um enunciado, isto é, se um enunciado obedece ou não às regras de funcionamento da língua. Ninguém comete erros ao falar sua própria língua materna, assim como ninguém comete erros ao 
andar ou respirar. Só se erra aquilo que é aprendido, naquilo que constitui um saber secundário, obtido por meio de treinamento, prática e memorização: erra-se ao tocar piano, erra-se ao dar um comando ao computador, erra-se ao escrever, porque a escrita é um aprendizado secundário (BAGNO 2015, p. 176).

Portanto, o/a falante de português tem conhecimento da língua que usa diariamente; o que ele/a pode não possuir é o conhecimento das regras da gramática normativa, mas isso ele/a pode aprender na escola. No entanto, não ter o domínio da norma-padrão não o/a impediu e não o/a impede de inter-agir em sociedade, pois todo falante dispõe de suficiente conhecimento linguístico em sua língua materna para produzir sentenças bem formuladas (BORTONI-RICARDO, 2004, p. 75).

É por isso que, na escola, é necessário realizar todos os esforços possíveis para aproveitar o espaço pedagógico com intuito de transformá-lo num "foco de resistência e combate ao preconceito linguístico e a toda forma de discriminação social", pois "negar o que é caracteristicamente nosso na língua é negar a nossa própria identidade cultural como povo e nação independente" (BAGNO, 2007, p. 157). Ou seja, a escola no lugar de disseminação do preconceito linguístico, poderia ser o lugar que permite "o convívio tranquilo e tolerante entre as muitas formas de se dizer a mesma coisa", é na escola que os/as alunos/as podem aprender a reconhecer a riqueza da língua, "e, por conseguinte, da nossa cultura e da nossa vida pessoal” (BAGNO, 2007, p. 158).

Sabe-se que a "norma-padrão tradicional é um patrimônio dos povos que falam o português, e todos esses falantes têm o direito de aprendê-la, por mais distante que ela esteja dos usos contemporâneos" (BAGNO, 2007, p. 158). O que não se pode aceitar é a imposição desse padrão como a única opção de uso da língua, pois, assim, não se estará proporcionando aos nossos/as alunos/as um ensino de língua pautado na realidade linguística dos/as estudantes e de suas comunidades.

A escola, como braço do Estado na construção dos cidadãos nacionais, sempre assumiu e ainda assume o papel de proporcionar ao/à aluno/a o aprendizado da normapadrão e das variedades cultas (a escola como espaço da cultura dominante, que é legitimada pelo Estado). Não estamos afirmando que estas não devam ser trabalhadas, pois elas são importantes para que o/a aluno/a possa usá-las em momentos em que seu projeto de dizer as requeira. Mas as outras variedades linguísticas devem ser respeitadas, valorizadas e legitimadas, porque elas são utilizadas nas interações entre pessoas de várias 
camadas sociais, de culturas diferentes, de modos distintos de pensar e de usar a língua. Elas carregam as experiências sociais desses grupos, os valores que os orientam; enfim, essas variedades linguísticas/línguas sociais dizem respeito às ideologias e lutas próprias dos grupos sociais que as utilizam.

Na verdade, concordamos com César e Cavalcanti (2007) quando defendem que as práticas linguísticas/culturais são perpassadas por diferentes dimensões ideológicas, uma vez que as línguas e suas práticas, vistas sob a perspectiva da metáfora do caleidoscópio, estão situadas em contextos específicos e, portanto, são utilizadas por sujeitos em práticas específicas, culturalmente, historicamente e socialmente situados, assim carregam consigo diferentes visões de mundo. E, como afirmam as autoras,

se os professores e teóricos procurarem sob o manto da "língua" a multiplicidade e complexidade linguística e cultural natural em qualquer comunidade ou sujeito falante, ao invés de procurar a "unidade" na diversidade; se encararmos realmente o múltiplo, as "misturas", as diferenças, ao invés de buscar as semelhanças estruturais para justificar uma pretensa "unidade sistemática da língua" ou mesmo um sistema que incorpore a variabilidade; se entendermos como multilinguismo o que chamamos de variação dialetal, seria mais fácil compreender e trabalhar com a pluralidade cultural dos usuários das escolas brasileiras (CÉSAR; CAVALCANTI, 2007 p. 62).

Em outras palavras, "se esquecermos as dicotomias língua e variedade, língua e norma, língua e dialeto, e tratarmos a variação dialetal como multilinguismo, aí a língua materna torna-se a "nossa língua" e não uma variedade corrompida - como normalmente é vista - da "língua portuguesa"” (CESAR; CAVALCANTI, 2007, p. 62). E ainda, "se considerarmos a pluralidade de contextos multiculturais em que é falada a língua portuguesa no Brasil, nada nos impede de afirmar que temos várias línguas sob o rótulo "língua portuguesa". É nesse sentido que essa perspectiva de língua pode ser aproximada da concepção de língua/linguagem do Círculo de Bakhtin, apresentada no tópico anterior.

Essa concepção de língua como caleidoscópio (que implica reconhecermos as diversas línguas sociais, as diversas cosmovisões, sob o rótulo de língua portuguesa) parece-nos mais adequada à realidade linguística do país, pois acreditamos que trabalhando em sala de aula com a concepção de que falamos "portugueses" e não "variedades" da língua portuguesa é o caminho para enfrentar uma das grandes dificuldades no ensino da língua materna, que é a ampliação do domínio da língua 
prestigiada (CÉSAR; CAVALCANTI, 2007, p. 63), que entraria como mais um recurso linguístico no amplo repertório dos falantes. Essa(s) língua(s) prestigiada(s) entraria(m) como mais uma língua social a que os falantes teriam acesso e fariam uso em função dos seus projetos de dizer, levando em consideração as lutas sociais implicadas nesses projetos.

Cox e Assis-Peterson (2007, p. 29) afirmam que a "língua é parte da cultura, ou seja, a língua categoriza o mundo natural e cultural e fornece pistas importantes sobre como estudar práticas e crenças culturais particulares". Sendo assim, não se pode ignorar o peso que a cultura do erro tem neste país - "peso que tem impedido uma discussão mais aberta e menos preconceituosa de nossa cara linguística real" (FARACO, 2008, p. 178).

O papel da escola é fazer com que o/a aluno/a entenda/aprenda como as línguas sociais funcionam nas práticas sociais; por isso, é importante ensiná-los/las a refletir sobre as escolhas dos recursos linguísticos, sobre as formas linguísticas em relação aos gêneros, aos projetos de dizer. Como formula Bagno (2007, p. 70), um ensino "sem preconceitos do funcionamento da língua, do modo como todo ser humano é capaz de produzir linguagem e interagir socialmente através dela", ou seja, "por meio de textos falados e escritos, portadores de um discurso". Para o autor, a tarefa da escola é construir o conhecimento dos/as alunos/as, sobre o funcionamento da linguagem, fazendo com que eles/elas percebam o quanto já sabem sobre a estrutura da língua "e como é importante se conscientizar desse saber para a produção de textos falados e escritos coesos, coerentes, criativos, relevantes, etc.” (BAGNO, 2007, p. 70).

Numa perspectiva da sociolinguística educacional, para que o ensino da língua portuguesa seja realizado mais de acordo com a realidade linguística do país, isto é, "mais sintonizada com a linguística contemporânea e com os objetivos de uma educação em língua materna que favoreça o letramento dos aprendizes" (BAGNO, 2013, p. 11), é fundamental que o/a professor/a possua uma formação que privilegie os aspectos linguísticos e não mais a pura gramática. Porém, isso não é fácil, pois muitos professores/as tiveram uma formação voltada para a gramática apenas e devido à carga horária pesada de trabalho ou até por falta de interesse, não conseguem buscar uma formação linguística mais atualizada, em que outras perspectivas de língua são estudadas. Outros profissionais, que tiveram uma formação linguística mais sintonizada com os estudos atuais, "quando chegam à escola repletos de ideias e inovações, veem-se 
impedidos de colocar em prática tudo o que aprenderam na faculdade", simplesmente porque "são obrigados a seguir um planejamento de aula que não permite a "fuga" ao conteúdo preestabelecido" (CHAMMA, 2007, p. 24).

Para além desta visão da sociolinguística educacional, partindo de uma concepção dialógica e sociológica de linguagem, como a apresentada anteriormente, não basta conhecer e mobilizar um amplo repertório linguístico. Cada língua social carrega valores que podem estar em luta umas contra as outras, uma vez que os grupos que as utilizam estão em luta/conflito. Sendo assim, é fundamental que a escola avance no sentido de trabalhar com os valores sociais que essas línguas carregam e de que estão carregadas. É fundamental, ainda, neste mesmo sentido, que a escola seja o espaço de reflexão sobre as ideologias linguísticas presentes na sociedade. Assim, o ensino da língua não se limita a ensinar outras línguas sociais, outras línguas portuguesas, que os/as alunos/as não conhecem, mas amplia seu campo de ação para refletir sobre os valores sociais, históricos e culturais relacionados a essas línguas e ao questionamento desses valores.

\section{A BASE NACIONAL COMUM CURRICULAR}

A preocupação do Estado Brasileiro com uma política educacional integrada e articulada vem sendo sinalizada desde a Constituição de 1988. Em 2017, o Ministério da Educação concluiu a sistematização da última versão da Base Nacional Comum Curricular (BNCC), a qual foi elaborada por especialistas e profissionais de ensino. O documento, que tem caráter normativo, passou por audiências públicas nas cinco regiões do país em busca de sugestões para seu aprimoramento.

A partir desse documento os sistemas e redes educacionais dos Municípios, Estados e Distrito Federal devem formular seus currículos. Segundo a BNCC, durante a Educação Básica os/as estudantes têm que ter garantido o desenvolvimento de dez competências gerais, perpassando os âmbitos pedagógicos, dos direitos de aprendizagem e desenvolvimento. Essas competências mobilizam habilidades, conhecimentos, atitudes e valores necessários para o pleno exercício da cidadania e do mundo do trabalho.

No entanto, afirmar que será garantido que todos/as alunos/as desenvolverão as dez competências gerais durante a Educação Básica sem dúvida é uma utopia. Sabemos que na prática nossos/as estudantes não recebem o mesmo ensino/aprendizagem, nem no mesmo 
município que residem, imagina no país. Isso ocorre por diversos fatores, entre eles o fato de o Brasil ser um país extenso em território e governado por diversas pessoas (com diferentes ideologias), as quais muitas vezes não veem a educação como uma prioridade. Existir um documento que norteia o ensino/aprendizagem do país, que idealiza que todos/as estudantes terão assegurados os mesmos direitos em relação a uma educação de qualidade não garante que na realidade isso de fato aconteça. Há Estados e Municípios que ainda não formularam um currículo de acordo com a BNCC, que enfrentam problemas seríssimos de estrutura, pois não "conseguem" fornecer nem pelo menos uma sala de aula minimamente adequada para as crianças. Como será garantido o desenvolvimento das dez competências gerais para esses/as estudantes?

A BNCC tem duas noções basilares, já previstas na LDB e na Constituição, que diz respeito à relação entre o que é básico-comum, as competências e diretrizes, e o que é diverso, os currículos, em matéria curricular. O comprometimento da BNCC está na “construção intencional de processos educativos que promovam aprendizagens sintonizadas com as necessidades, as possibilidades e os interesses dos estudantes e [...] desafios da sociedade contemporânea" (BRASIL, 2017, p. 14). De acordo com o documento os estudantes são vistos como sujeitos de aprendizagem, de forma plural, singular e integral e sua educação é promovida para acolher, reconhecer e desenvolver plenamente, nas suas singularidades e diversidades.

Sem dúvida, esse discurso é lindo, resta-nos saber se na prática, em relação ao ensino/aprendizagem da língua portuguesa a implementação de um currículo único não vai reforçar uma visão de cultura homogênea, como já afirmado anteriormente, assim como de língua única/homogênea, pois sabemos que no Brasil, as práticas pedagógicas para o ensino/aprendizagem da língua portuguesa sempre refletiram o ideal do monolinguísmo (CÉSAR; CAVALCANTI, 2007), apesar de os documentos oficiais anteriores terem afirmado que as variedades linguísticas deveriam ser respeitadas e trabalhadas em sala de aula, o foco sempre foi trabalhar com a norma culta da língua. Por isso é importante analisar a nova BNCC, para verificar como é abordado o fenômeno da heterogeneidade/variação linguística e, consequentemente, que ideologia(s) linguística(s) está(ão) presente(s) no documento, ou seja, que ideologia(s) linguística(s) deverá(ão) estar presente(s) nas salas de aula do país, pois essas ideologias afetam o ensino/aprendizagem da língua portuguesa, uma vez que deixando de abordar de maneira mais significativa a 
diversidade linguística e cultural, continuaremos a amargar baixos índices e, principalmente, o insucesso escolar de nossos/as estudantes.

\section{AS DIRETRIZES PARA O ENSINO DE LÍNGUA PORTUGUESA DE ACORDO COM A BNCC}

O objetivo específico deste trabalho é analisar Base Nacional Comum Curricular (BNCC) no que se refere ao ensino/aprendizagem da Língua Portuguesa, com o intuito de observar que orientações fornecem sobre o ensino da língua, que funções atribuem a ela, que valores associam à língua; desta forma, identificamos a(s) ideologia(s) linguísticas para o ensino da língua portuguesa no país.

Podemos perceber que a BNCC mantém muitos dos princípios já adotados nos Parâmetros Curriculares Nacionais (PCNs), já que a centralidade no texto e nos gêneros textuais permanece, ou seja, continua assumindo a perspectiva enunciativa-discursiva de linguagem. O que é muito importante, porque não se pode pensar em um ensino de língua portuguesa de maneira descontextualizada, sem articular os usos sociais da língua, uma vez que "todos os diversos campos da atividade humana estão ligados ao uso da linguagem” Bakhtin (2011, p. 261).

Ao assumir a perspectiva enunciativo-discursiva de linguagem, podemos inferir que a BNCC se fundamenta na concepção de linguagem como forma de interação humana, entendendo que os sujeitos se comunicam discursivamente em situações reais e concretas de interação. Sabemos que na abordagem dialógica, o enunciado, enquanto materialização do discurso, corresponde à linguagem em uso, na prática, de modo real, muito diferentemente das unidades como a palavra e a frase, em razão de que, como já afirmado anteriormente, "o emprego da língua efetua-se em forma de enunciados (orais e escritos) concretos e únicos, proferidos pelos integrantes desse ou daquele campo da atividade humana" (BAKHTIN, 2011, p. 261). Dessa maneira, não faz sentido o estudo de unidades isoladas, posto que o texto é produto de uma atividade discursiva onde o sujeito diz algo a alguém com a intenção de produzir enunciados, por essa razão o texto ganha centralidade no ensino da linguagem. Sendo assim, as habilidades apresentadas abaixo demonstram a visão da BNCC no que se refere à concepção de linguagem e no texto como o ponto dominante no ensino da linguagem: 
Explorar e analisar espaços de reclamação de direitos e de envio de solicitações (tais como ouvidorias, SAC, canais ligados a órgãos públicos, plataformas do consumidor, plataformas de reclamação), bem como de textos pertencentes a gêneros que circulam nesses espaços, reclamação ou carta de reclamação, solicitação ou carta de solicitação, como forma de ampliar as possibilidades de produção desses textos em casos que remetam a reivindicações que envolvam a escola, a comunidade ou algum de seus membros como forma de se engajar na busca de solução de problemas pessoais, dos outros e coletivos (BRASIL, 2017, p. 164-165)

A BNCC inova em relação aos PCNs ao inserir a análise semiótica, o que demonstra que observaram/consideraram ao preparar o documento as mudanças nos estudos de linguagens e na sociedade, principalmente em relação aos usos das tecnologias, uma vez que percebemos que a modificação nos usos da linguagem, em decorrência do surgimento das TICS, reflete na inclusão intensificada dos gêneros discursivos/textuais/ multissemióticos que emergem da cultura digital no nosso cotidiano. Como demonstrado na BNCC:

Produzir resenhas críticas, vlogs, vídeos, podcasts variados e produções e gêneros próprios das culturas juvenis (algumas possibilidades: fanzines, fanclipes, e-zines, gameplay, detonado etc.), que apresentem/descrevam e/ou avaliem produções culturais (livro, filme, série, game, canção, disco, videoclipe etc.) ou evento (show, sarau, slam etc.), tendo em vista o contexto de produção dado, as características do gênero, os recursos das mídias envolvidas e a textualização adequada dos textos e/ou produções (BRASIL, 2017, p. 162-163).

De acordo com o documento, "as práticas de linguagem contemporâneas não só envolvem novos gêneros e textos cada vez mais multissemióticos e multimidiáticos, como também novas formas de produzir, de configurar, de disponibilizar, de replicar e de interagir" (BRASIL, 2017, p. 66).

Contudo, é pertinente refletir como esses gêneros serão trabalhados em sala de aula, uma vez que muitos/as docentes não os conhecem/dominam, e também não podemos afirmar que a maioria dos/as estudantes já fazem usos desses gêneros no cotidiano, porque estão mais "conectados" com as novas tecnologias. Na verdade, infelizmente, muitas escolas ainda possuem poucos recursos tecnológicos, algumas nem acesso à internet têm e os/as docentes não dispõem de uma formação para trabalhar em sala de aulas com textos 
multimodais. Os/as alunos/as, por sua vez, até têm celulares, mas com acesso limitado à internet e acabam utilizando, na sua maioria, apenas as redes sociais. O ensino remoto provou como são grandes as desigualdades, pois muitos/as estudantes não conseguiram acompanhar as aulas on-line por não terem computadores, celulares, acesso à internet e acabaram tendo que buscar as atividades impressas nas escolas para poder acompanhar minimamente os conteúdos que estão sendo "trabalhados".

É importante observar que a BNCC "procura contemplar a cultura digital, diferentes linguagens e diferentes letramentos, desde aqueles basicamente lineares, com baixo nível de hipertextualidade, até aqueles que envolvem a hipermídia” (BRASIL, 2017, p. 68), isto é, trabalhar com um ensino de língua onde os gêneros discursivos estão relacionados com o diálogo e com diferentes visões de mundo, diferentes conjuntos valorativos que orientam os grupos e os sujeitos na sociedade, o que permite relacionarmos essa concepção de ensino de língua à perspectiva bakhtiniana.

Essa abordagem vai ao encontro também com as reflexões de Marcos Bagno, pois para o estudioso "uma coisa é aprender sobre a língua, outra coisa, muito diferente, é aprender a usar a língua” (BAGNO, 2011, p. 145). É fato, que os/as alunos/as passam anos na escola, estudando sobre a tal norma-padrão e frequentemente não a dominam, visto que, o foco do ensino está na metalinguagem, no falar sobre a língua, com poucas oportunidades de uso efetivo. Neste sentido, merece destaque valorizar a principal contribuição da BNCC, que é demandar o protagonismo dos/as estudantes durante toda a Educação Básica. Para isso, o documento leva em conta os principais campos da atividade humana: a vida cotidiana; a vida pública; as práticas de estudo e pesquisa; o artístico/literário. Com essa divisão se consegue alcançar com mais profundidade os diversos usos da/s língua/s brasileiras.

No entanto, sabemos que são muitos os desafios enfrentados para desenvolver atividades na perspectiva dos multiletramentos e a inserção de gêneros da cultura digital na escola, visto que falta formação docente e a disponibilidade de recursos tecnológicos, como já afirmado anteriormente. É fato que muitas escolas nem acesso à internet têm para disponibilizar aos/as seus/suas docentes, e muito menos para os/as alunos/as. Sendo assim, não basta apenas a boa vontade de professores/as e equipe gestora da escola para realizar um trabalho/ensino de acordo com que é apontado na BNCC e, principalmente, nas necessidades dos/das estudantes, há várias outras questões que envolvem as demandas 
tecnológicas (que caberia um estudo somente sobre esse assunto), que limitam o acesso aos ambientes digitais no âmbito da escola pública.

É evidente que é muito importante e fundamental que haja o trabalho/ensino/ aprendizagem com os gêneros da cultura digital em sala de aula, mas não adianta a BNCC apontar essa necessidade se não houver investimentos em tecnologias (um gigante desafio) e na formação de professores/as.

Outro ponto importante da BNCC é a valorização da diversidade cultural, uma vez que além de ser apontado a importância de se organizar as práticas em sala de aula em consonância com os eixos temáticos e os campos de atuação, a Base alerta para consciência ao selecionar conteúdos que exprimem a diversidade humana cultural do Brasil no momento de preparar as aulas, pois "se estima que mais de 250 línguas são faladas no país - indígenas, de imigração, de sinais, crioulas e afro-brasileiras, além do português e de suas variedades", e esse "patrimônio cultural e linguístico é desconhecido por grande parte da população brasileira (BRASIL, 2017, p. 68). Essa visão permite "reverter a situação de exclusão histórica dos grupos marginalizados, por meio da igualdade de oportunidades para ingressar e permanecer na escola" (SOUZA, 2019, p.111).

No entanto, é pertinente refletir até que ponto se está realmente valorizando a diversidade cultural. Essa valorização se estende ao trabalho com todos os campos de atuação ou é reservado apenas para o campo artístico-literário. Lembrando que valorizar a diversidade cultural no ensino/aprendizagem da língua portuguesa é oportunizar aos/às estudantes uma ampliação de repertório, de interação com culturas, línguas e usos linguísticos diversificados, o que o Círculo de Bakhtin já defendia há muito tempo atrás. Considerando que os sujeitos circulam por diferentes esferas sociais e levam usos e formas linguísticas de uma esfera para a outra, "mobilizando na produção de seus enunciados formas lexicológicas, morfológicas, sintáticas, semânticas (no sentido de valorativas) e textuais que não seriam comuns a um determinado campo ou algum gênero (TORQUATO, 2020, no prelo). Essa movimentação possibilita aos sujeitos dialogarem com visões de mundo e universo de valores distintos, que podem ser semelhantes ou contraditórios. Circular por distintas esferas e dialogar com vários universos valorativos possibilita ao/à estudante compreender que às vezes mobiliza valores contraditórios em seus próprios enunciados. 
Assim, quando a BNCC assinala a necessidade de "discutir, no fenômeno da variação linguística, variedades prestigiadas e estigmatizadas e o preconceito linguístico que as cerca, questionando suas bases de maneira crítica" (BRASIL, 2017, p. 83) percebemos a possibilidade de explorar no ensino/aprendizagem da língua portuguesa os valores atribuídos às formas e usos linguísticos, ou seja, às línguas sociais na perspectiva bakhtiniana.

Sendo assim, o papel da escola é fazer, como já mencionado, com que o/a aluno/a entenda/aprenda como as línguas sociais funcionam nas práticas sociais, ou seja, ensinálos/las a refletir sobre as escolhas dos recursos linguísticos, sobre as formas linguísticas em relação aos gêneros, aos projetos de dizer.

No entanto, em relação ao ensino/aprendizagem da análise linguística percebemos que na BNCC as questões gramaticais estão mais visíveis em relação aos PCNs, pois são indicados os conteúdos que são necessários ensinar/aprender em cada ano. Porém, a proposta é que a gramática seja compreendida em seu funcionamento e não como um conteúdo em si, de forma descontextualizada das práticas sociais, ou seja, das diversas maneiras de usos da língua. Com podemos observar nos seguintes fragmentos:

Identificar o uso de recursos persuasivos em textos argumentativos diversos (como a elaboração do título, escolhas lexicais, construções metafóricas, a explicitação ou a ocultação de fontes de informação) e perceber seus efeitos de sentido (BRASIL, 2017, p. 160-161).

Analisar o uso de recursos persuasivos em textos argumentativos diversos (como a elaboração do título, escolhas lexicais, construções metafóricas, a explicitação ou a ocultação de fontes de informação) e seus efeitos de sentido (BRASIL, 2017, p. 174-175).

Como podemos perceber as habilidades apontam para o movimento metodológico do uso/reflexão a partir do trabalho com os gêneros discursivos/textuais visando levar o/a aluno/a a refletir sobre como as escolhas linguísticas textuais/discursivas contribuem para a construção de sentidos, ou seja, de acordo com a BNCC, no ensino/aprendizado da gramática não cabe mais a memorização de regras, mas, sim, a compreensão das formas de uso de acordo com os projetos de dizer.

Diante disso, percebemos que a BNCC está deixando claro que no processo de ensino/aprendizagem de uma língua não se deve priorizar o ensino sistemático da língua, 
mas, sim, o seu uso nas diversas relações sociais, como ela é carregada ideologicamente/valorativamente nas diversas esferas da atividade humana.

No entanto, ainda aparece no documento a terminologia "correta/corretamente" quando se fala, principalmente, da escrita, como por exemplo: "utilizar, ao produzir o texto, grafia correta das palavras..." (BRASIL, 2017, p. 97); "ler e escrever corretamente" (p. 99); reconhecer e grafar, corretamente, as palavras..." (p. 117); "escrever textos corretamente..." (p. 185), etc. Acreditar que o "erro" empobrece a língua é, sem dúvida, um ponto de vista dos puristas, de quem acredita que a língua é homogênea e não observa/aceita os movimentos/mudanças que ocorrem nela ao longo do tempo (BAGNO, 2015).

A BNCC, ao colocar em evidência os estudos sobre a norma-padrão, revela, teoricamente, "um conflito na concepção de linguagem como ação dialógica, porque ignora a realidade sócio-historicamente construída pelos sujeitos que ocupam lugares sociais e falam a partir desses lugares" (SOUZA, 2019, p. 181). Sem dúvida, como afirma Souza (idem) "linearizar o conhecimento sobre a língua e sobre a norma-padrão significa reduzir o conhecimento a "bons usos", tomando como padrão ou modelo uma língua idealizada cujas regras são de caráter prescritivo-normativo, tal qual as abordadas pelas gramáticas tradicionais". Segundo a autora, "ainda que o documento oriente o estudo de "outras variedades", fragiliza-se com o estabelecimento da norma-padrão e a listagem de conteúdos dissociados de práticas situadas de linguagem”, como podemos perceber no excerto abaixo:

Reconhecer recursos de coesão referencial: substituições lexicais (de substantivos por sinônimos) ou pronominais (uso de pronomes anafóricos - pessoais, possessivos, demonstrativos) (BRASIL, 2017, p.162-163).

O enfoque no processo de ensino/aprendizagem dos conteúdos gramaticais como objetos de ensino, afasta-se da perspectiva da prática de análise linguística, vista como um processo reflexivo sobre os usos da língua/linguagem.

Portanto, sabendo que o/a falante tem conhecimento da língua que usa diariamente, seria mais pertinente utilizar a terminologia "de acordo com a variedade culta" no momento que for solicitado a produção textual de determinados gêneros que requerem um maior grau de monitoramento. Falar em "erro" faz com que os/as alunos/as acreditem que 
não sabem fazer uso da língua portuguesa, o que acaba gerando preconceito linguístico no ambiente escolar e uma desvalorização dos sujeitos.

Refletindo sobre a prática linguística, é fato que há mais de duas décadas, já dispúnhamos de parâmetros curriculares que sinalizavam a prática de análise linguística como conteúdo de ensino, o fato é que esperávamos que no novo documento houvesse uma atualização de acordo com os estudos mais atuais sobre o ensino/aprendizagem da língua portuguesa que evidenciam a importância de se trabalhar em sala de aula com os usos da linguagem, isto é, trabalhar com as valorações atribuídas as escolhas linguísticas dos falantes.

Finalizando essa breve análise da Base, notamos que houve um avanço para o ensino/aprendizagem da língua portuguesa com a implantação da BNCC, ao se propor um ensino de língua mais pautado na realidade linguística do país e na inclusão dos gêneros discursivos/textuais/multissemióticos. É sinalizada a importância de que o ensino da língua portuguesa não tenha como foco o ensino da gramática normativa, mas sim que o/a aluno/a reflita sobre os usos da linguagem. No entanto, o documento reforça o monolinguismo da língua portuguesa e a escrita como lugar da norma de prestígio, portanto, como lugar de uma certa normatização, como já acontecia nos Parâmetros Curriculares Nacionais (PCN). Ainda que não seja o espaço do que prescreve a gramática, é o lugar da língua de prestígio e, portanto, da língua legítima, da língua de poder (BAKHTIN, 2015), da língua única. Nesse sentido, a escrita é o espaço da normatização; não a norma das gramáticas tradicionais, mas a norma do bem escrever e do bem falar dos grupos de elite. É importante refletir sobre a(s) ideologia (s) linguísticas presentes na BNCC, porque esse documento servirá de guia para produção de livros didáticos, influenciará nas avaliações de larga escala e na formação de professores/as, consequentemente, será diretriz para o ensino de língua portuguesa em todo território nacional.

\section{CONSIDERAÇÕES FINAIS}

Este artigo buscou identificar a/as ideologia/s presentes na BNCC. Para isso, foi mobilizado o arcabouço teórico da Linguística Aplicada, fazendo ligação entre língua e sociedade à luz dos estudos do Círculo de Bakhtin e das contribuições da Sociolinguística. 
Para Bakhtin e o Círculo, a linguagem deve ser entendida como prática viva entre sujeitos dialógicos, e o emprego da língua se efetua em forma de enunciados, sejam orais ou escritos, de acordo com a necessidade/finalidade do processo de interação. Essa mesma concepção de linguagem fundamenta a Base Nacional Comum Curricular (BNCC) de modo que é necessário que o/a docente tenha consciência de que no processo de ensino/aprendizagem $\mathrm{da}(\mathrm{s})$ língua(s) portuguesa(s), ele/ela está trabalhando com enunciados, dirigidos a alguém e orientados por um projeto de dizer. A BNCC deixa claro que é importante que o/a professor/a tenha em mente que a língua incorpora e articula a experiência social.

Assim como os PCNs, a BNCC afirma que não se pode negar o conhecimento que os/as alunos/as já possuem, pois eles foram adquiridos com as experiências no convívio social, nos usos linguísticos nas interações. A linguagem, assim apreendida pelos/as estudantes, está articulada com as ações deles como falantes no mundo nos diversos campos da atividade humana (BAKHTIN, 2011) de que participam.

Nesta breve análise da BNCC identificamos que já não há uma predominância da ideologia da padronização - orientada então para a língua única, mas, sim, a valorização da multiculturalidade e das diversas maneiras de usar a língua nos diversos campos da atividade humana, ou seja, de acordo com a Base para o ensino/aprendizagem de língua/linguagem é fundamental trabalhar com enunciados, isto é, com as várias manifestações concretas de uso da linguagem, uma vez que essas manifestações compreendem uma ampla gama de diversidade linguística. Além disso, é essa concepção de língua como interação, dialógica e sociológica, que é adotada pelo documento.

No entanto, quando o assunto é a análise linguística a BNCC deixa a desejar, pois distancia, na sua maioria, da perspectiva da prática de análise linguística, uma vez que ao listar as habilidades, segue a organização cumulativa da gramática tradicional normativa, afastadas do texto/gêneros e, por conseguinte, concentradas nas unidades menores, sem conexão com as práticas de linguagem. E ainda, utiliza-se do termo "corretamente" para as produções textuais, reforçando a cultura/ideologia do erro, a crença da correção.

Enfim, podemos dizer que houve um avanço para o ensino/aprendizagem da língua portuguesa, quando o documento vê a língua como sempre em movimento nas interações (nas quais os sujeitos precisam partilhar os presumidos e (re)conhecer os conjuntos de valores mobilizados nas línguas sociais, nos enunciados). E também quando reconhece o 
Brasil como um país multilíngue e multicultural. No entanto, como afirmado anteriormente, quando ainda se utiliza de termos como "corretamente", "correto" para as produções textuais age de maneira incoerente com o que é proposto em relação ao ensino/aprendizagem de línguas em uma perspectiva dialógica-discursiva. Essa incoerência prejudica o ensino/aprendizagem, uma vez que pode confundir os/as docentes que não possuem uma formação mais de acordo com as pesquisas atuais sobre o ensino de línguas.

É importante ressaltar, para que haja um ensino/aprendizado eficaz, não basta ter um documento com ótimas diretrizes se não houver investimento na formação de professores/as, pois são eles/elas que de fato estão na linha de frente, são esses profissionais que transmitem ideologias linguísticas.

Acreditamos que este artigo contribui para as discussões sobre o ensino de língua portuguesa e para a formação de professores da área, segundo a proposta de Moita Lopes (2013), que nos instiga a repensar o que chamamos de português no século XXI e, consequentemente, os demais conceitos que contribuem para um tratamento que desconsidere as instáveis relações sociais de modo que colabore para práticas pedagógicas reflexivas em relação a ideologias linguísticas que estão envolvidas no processo de ensino/aprendizagem de línguas.

\section{REFERÊNCIAS}

BAGNO, M. Sete erros aos quatro ventos a variação linguística no ensino do português. São Paulo: Parábola, 2015.

. Nada na língua é por acaso por uma pedagogia da variação linguística. São Paulo: Parábola Editorial, 2007.

Sete erros aos quatro ventos a variação linguística no ensino do português. São Paulo: Parábola, 2013.

Preconceito linguístico. São Paulo: Loyola, 2011

BAKHTIN, M; VOLOCHÍNOV, V. N. Marxismo e filosofia da linguagem. 13.ed. São Paulo: Hucitec, 2009.

Marxismo e filosofia da linguagem. São Paulo: Hucitec, 1995. 
Estética da Criação Verbal. 6.ed. São Paulo: Martins Fontes, 2011.

Teoria do romance I. São Paulo: Editora 34, 2015.

BRASIL. Ministério da Educação. Secretaria de Educação Básica. Base Nacional Curricular BNCC. Brasília, 2017.

Parâmetros Curriculares Nacionais (PCNS). Língua Portuguesa. Ensino Fundamental. Terceiro e quarto ciclos. Brasília: MEC/SEF, 1998.

BORTONI-RICARDO, S. M. Educação em Língua Materna: a sociolinguística na sala de aula. São Paulo: Parábola, 2004.

CAVALCANTI, M. C. Educação linguística na formação de professores de línguas: intercompreensão e práticas translíngues. In. MOITA LOPES, L.P. (Org.) Linguística Aplicada na Modernidade recente. São Paulo: Parábola, 2013, p. 211-226.

Estudos sobre educação bilíngue e escolarização em contextos de minorias linguísticas no Brasil. DELTA, 1999, vol.15, p.385-417.

CAVALCANTI, M. C.; CÉSAR, A. L. Do singular para o multifacetado: o conceito de língua como caleidoscópio. In. CAVALCANTI, M. C; BORTONI-RICARDO, S. T. (Orgs.) Transculturalidade, linguagem e educação. Campinas, SP: Mercado de Letras, 2007, p. 45-65.

ELICHIRIGOITY, M. T. A formação do sentido e da identidade na visão Bakhtiniana. Cadernos de Letras da UFF, Dossiê: Literatura, língua e identidade, 2008, n. 34, p. 181206.

CHAMMA, L. A variação linguística nos livros didáticos de português ( $5^{a}$ a $8^{a}$ séries). Dissertação (Mestrado em Linguística) - Instituto de Letras, Universidade de Brasília, Brasília, 2007.

COX, M. I. P; ASSIS-PETERSON, A. A. Transculturalidade e transglossia: para compreender o fenômeno das fricções linguístico-culturais em sociedades contemporâneas sem nostalgia. In. CAVALCANTI, M.C; BORTONI-RICARDO, S. T. (Orgs.) Transculturalidade, linguagem e educação. Campinas - SP: Mercado de Letras, 2007, p. 23-43.

EAGLETON, T. A ideia de cultura, 2ed. São Paulo: UNESP, 2011.

FARACO, C. A. Norma culta brasileira desatando alguns nós. São Paulo: Parábola, 2008.

KROSKRITY. Language Ideologies. In: DURANTI, A. (org.) A Companion to Linguistic Anthropology: Blackwell, Oxford, 2004. 
MILROY, J. Ideologias linguísticas e as consequências da padronização. In: BAGNO, M.; LAGARES, X. (Orgs.). Políticas da norma e conflitos linguísticos. São Paulo, SP: Parábola, 2011, p. 49-87.

MOITA LOPES, L. P. da. O português no século XXI cenário geopolítico $e$ sociolinguístico. São Paulo, SP: Parábola, 2013.

SIGNORINI, I. Invertendo a lógica do projeto escolar de esclarecer o ignorante em matéria de língua. Scripta, Belo Horizonte, v.7, n.14. p. 90-99, 2004.

SANTANA. A. N. A variação no livro didático e na prática docente de língua portuguesa: políticas e ideologias linguísticas. Dissertação (Mestrado em Estudos da Linguagem), Universidade Estadual de Ponta Grossa, Paraná, 2017.

SOUZA, E. K. Ensino de Língua Portuguesa na Base Nacional Comum Curricular (BNCC): criando inteligibilidade para a prática de análise linguística. Dissertação (Mestrado Profissional em Letras), Universidade Federal de Santa Catarina, Florianópolis, SC, 2019.

TORQUATO. C. P. Eu gosto muito de interpretar esses dados sob uma outra ótica: desregulamentação e (de)colonialidade linguística no ensino de língua. Campinas, SP. No prelo.

WOOLARD. K. A. Language Ideology as a Field of Inquiry: New York: Oxford University Press, 1998.

Recebido em: 27 abr. 2020.

Aceito em: 05 out. 2020. 